Article

\title{
Synthesis of Copper Nanoparticles Stabilized with Organic Ligands and Their Antimicrobial Properties
}

\author{
Noemi Jardón-Maximino ${ }^{1}$, Marissa Pérez-Alvarez ${ }^{1, *(\mathbb{C}}$, Gregorio Cadenas-Pliego ${ }^{1, *(\mathbb{D}}$, Luis E. Lugo-Uribe ${ }^{2} \mathbb{D}$, \\ Christian Cabello-Alvarado ${ }^{1,3}{ }^{(1)}$, José M. Mata-Padilla ${ }^{1}{ }^{1}$ and Enrique Díaz Barriga-Castro ${ }^{1}$ \\ 1 Centro de Investigación en Química Aplicada (CIQA), Saltillo 25294, Coahuila, Mexico; \\ jardonmaximino@gmail.com (N.J.-M.); christian.cabello@ciqa.edu.mx (C.C.-A.); \\ jose.mata@ciqa.edu.mx (J.M.M.-P.); enriquediaz.barriga@ciqa.edu.mx (E.D.B.-C.) \\ 2 Centro de Tecnología Avanzada CIATEQ, Lerma 52004, Estado de México, Mexico; luis.lugo@ciateq.mx \\ 3 CONACYT-Centro de Investigación y de Innovación del Estado de Tlaxcala, \\ Tlaxcala C.P. 90000, Tlaxcala, Mexico \\ * Correspondence: pamarissa@hotmail.com (M.P.-A.); gregorio.cadenas@ciqa.edu.mx (G.C.-P.)
}

\section{check for}

updates

Citation: Jardón-Maximino, N.; Pérez-Alvarez, M.; Cadenas-Pliego,

G.; Lugo-Uribe, L.E.;

Cabello-Alvarado, C.; Mata-Padilla,

J.M.; Barriga-Castro, E.D. Synthesis of

Copper Nanoparticles Stabilized with

Organic Ligands and Their

Antimicrobial Properties. Polymers

2021, 13, 2846. https://doi.org/

$10.3390 /$ polym 13172846

Academic Editor: Helena Felgueiras

Received: 29 July 2021

Accepted: 18 August 2021

Published: 25 August 2021

Publisher's Note: MDPI stays neutral with regard to jurisdictional claims in published maps and institutional affiliations.

Copyright: (c) 2021 by the authors. Licensee MDPI, Basel, Switzerland. This article is an open access article distributed under the terms and conditions of the Creative Commons Attribution (CC BY) license (https:/ creativecommons.org/licenses/by/ $4.0 /)$

\begin{abstract}
In this work, we report the synthesis of copper nanoparticles (Cu NPs), employing the chemical reduction method in an aqueous medium. We used copper sulfate pentahydrate $\left(\mathrm{CuSO}_{4} \cdot 5 \mathrm{H}_{2} \mathrm{O}\right)$ as a metallic precursor; polyethylenimine (PEI), allylamine (AAM), and 4-aminobutyric acid (AABT) as stabilizing agents; and hydrated hydrazine as a reducing agent. The characterization of the obtained nanoparticles consisted of X-ray, TEM, FTIR, and TGA analyses. Through these techniques, it was possible to detect the presence of the used stabilizing agents on the surface of the NPs. Finally, a zeta potential analysis was performed to differentiate the stability of the nanoparticles with a different type of stabilizing agent, from which it was determined that the most stable nanoparticles were the $\mathrm{Cu}$ NPs synthesized in the presence of the PEI/AAM mixture. The antimicrobial activity of $\mathrm{Cu} / \mathrm{PEI} / \mathrm{AABT}$ toward P. aeruginosa and S. aureus bacteria was high, inhibiting both bacteria with low contact times and copper concentrations of 50-200 ppm. The synthesis method allowed us to obtain $\mathrm{Cu}$ NPs free of oxides, stable to oxidation, and with high yields. The newly functionalized $\mathrm{Cu}$ NPs are potential candidates for antimicrobial applications.
\end{abstract}

Keywords: chemical reduction method; copper nanoparticles; polyethylenimine; zeta potential; antimicrobial

\section{Introduction}

Copper has been identified as a material with excellent antimicrobial properties, as it can efficiently eliminate fungi, bacteria, and viruses [1]. The antimicrobial activity of copper was demonstrated with the emergence of the COVID-19 pandemic, since copper was able to inactivate the novel coronavirus (SARS-CoV-2) in shorter times compared to other materials [2].

Regarding $\mathrm{Cu}$ NPs, several papers have recently highlighted their importance in priority areas for humankind, for instance, in medical (the COVID-19 pandemic) [3,4], farming [5-8], and environmental applications [9,10], among others. As with other metallic nanoparticles (M NPs), Cu NPs have been widely studied due to their antimicrobial, electrical, thermal conductivity, catalytic, and optical properties [11].

The development of polymeric composites is an important application of M NPs [12]. Some material properties, such as electrical, mechanical, thermal, and antimicrobial properties, have been improved by the incorporation of M NPs into polymeric matrices [13-15]. Nevertheless, there are important difficulties to obtaining M NPs polymeric composites with a suitable dispersion due to the strong tendency of the M NPs to agglomerate, as well as their incompatibility with the polymeric matrix [14,15]. An effective strategy employed to overcome these problems involves the functionalization of M NPs with organic ligands or polymers [12]. 
The attractiveness of $\mathrm{Cu}$ NPs is mainly due to their higher abundance and lower cost compared to gold and silver nanoparticles [1,16]. An important disadvantage of $\mathrm{Cu}$ NPs is that they are easily oxidized. However, the oxidation problem can be avoided using stabilizing agents, such as organic ligands or polymers, during the synthesis of the nanoparticles [17].

Several methods have been developed to synthesize $\mathrm{Cu}$ NPs, with the chemical reduction and green synthesis methods being the most studied. Green synthesis is a simple and low-cost method which leads to stable products. The green synthesis method is environmentally friendly, since the chemical reduction agents are replaced by nontoxic natural compounds [16]. An example of this green route is the synthesis of Cu NPs in the presence of cotton without the addition of chemical reducing agents, which exclusively produces oxidation-stable $\mathrm{Cu}$ NPs in a facile manner [18]. On the other hand, the method of chemical reduction in an aqueous medium is one of the most widely used for Cu NPs synthesis due to the water's capability to dissolve a wide variety of metallic salts and the method's reproducibility $[19,20]$. Using this method, it is possible to control the size, morphology, and composition of $\mathrm{Cu}$ NPs by varying the experimental conditions, such as the concentration of reagents, temperature, solvents, metal precursor, reducing agent, and stabilizing agents that prevent the aggregation of nanoparticles, as well as the nature of the dispersing medium [21-23].

The effect of the experimental conditions on the synthesis of $\mathrm{Cu}$ NPs has been studied with the chemical reduction method. Copper ions can be reduced to $\mathrm{Cu}, \mathrm{Cu}_{2} \mathrm{O}$, or $\mathrm{CuO}$ depending on the reducing power of the reducing agent [22]. Some reports have suggested that $\mathrm{pH}$ values in the reaction medium between 9 and 10.5 have an influence on obtaining pure $\mathrm{Cu}$ NPs. A mixture of $\mathrm{Cu}$ and $\mathrm{Cu}_{2} \mathrm{O}$ nanoparticles was achieved at $\mathrm{pH}$ values as high as 12. At low $\mathrm{pH}$ values, the formation of $\mathrm{CuO}$ and $\mathrm{Cu}_{2} \mathrm{O}$ is prevented [22-25]. In addition, by varying the concentration of the stabilizing agent, the size and shape of the nanoparticles can be controlled [23]. Wang and coworkers reported a synthesis route in an aqueous medium to produce $\mathrm{Cu}$ NPs with a controlled size and composition, employing copper (II) salt, hydrazine, and poly (acrylic acid) (PAA). The authors controlled the Cu NPs size by varying the PAA concentration, obtaining an average particle size (APS) ranging from 30 to $80 \mathrm{~nm}$ [24]. Lai and coworkers synthesized $\mathrm{Cu}$ NPs in an aqueous medium using $\mathrm{CuSO}_{4} \cdot 5 \mathrm{H}_{2} \mathrm{O}$, polyvinylpyrrolidone (PVP), and sodium hypophosphite. The authors observed that, with a higher PVP concentration, the overgrowth of the Cu NPS was prevented [22]. Wang and Asefa reported the synthesis of $\mathrm{Cu}$ NPs of uniform size using $\mathrm{CuSO}_{4} \cdot 5 \mathrm{H}_{2} \mathrm{O}$, hydrazine, poly(allylamine) (PAAm), and $\mathrm{NaOH}$ to control the solution's $\mathrm{pH}$. PAAm had an important effect on the long-term stability of the $\mathrm{Cu}$ NPs [23]. The production of $\mathrm{Cu}$ NPs composed exclusively of $\mathrm{Cu}(0)$, free of $\mathrm{CuO}$ and $\mathrm{Cu}_{2} \mathrm{O}$, increased the number of applications, presented a higher effectiveness in antimicrobial activity, and were less cytotoxic compared to $\mathrm{CuO}$ nanoparticles [26]. Recently, our research group reported the synthesis of $\mathrm{Cu}$ NPs by chemical reduction in an aqueous solution and constant basic $\mathrm{pH}$, using nitrogen-based ligands as stabilizing agents. With our method, the production of $\mathrm{CuO}$ and $\mathrm{Cu}_{2} \mathrm{O}$ depended on the type and amount of the ligand utilized during the synthesis process. The $\mathrm{Cu}$ NPs coated with nitrogen-based ligands were stable to oxidation under ambient conditions for long-term periods after being synthesized, as they did not undergo oxidation after $3-5$ years of storage. The nitrogen-based ligand content in the $\mathrm{Cu}$ NPs ranged from $1.3 \mathrm{wt}$ \% $\%$ to $5.1 \mathrm{wt} . \%[20,27,28]$.

Currently, polyethylenimine (PEI), a highly branched cationic polymer, is of great interest in the synthesis of M NPs in aqueous media [29]. PEI acts as a reactive template in which amino groups coordinate with metal ions dissolved in water, reducing the aggregation capability of the M NPs due to the steric hindrance provided by the PEI [30-32]. Pulkkinen and coworkers compared PEI and tetraethylenepentamine (TEPA) in the synthesis of Cu NPs. They observed that the higher amino groups' content of PEI promoted the formation of smaller $\mathrm{Cu}$ NPs. The average particle size of the nanoparticles was $8.5 \mathrm{~nm}$ for PEI and $19.4 \mathrm{~nm}$ for TEPA [17]. A similar effect was reported by Bowen Wang and coworkers. 
The authors synthesized $\mathrm{Cu}$ NPs in the presence of PEI, observing that the Cu NPs size was reduced with an increment in PEI concentration. This behavior was attributed to an anchorage of the $\mathrm{Cu}$ NPs to the PEI polymeric chain, reducing the aggregation capability of the $\mathrm{Cu}$ NPs [11].

In this study, $\mathrm{Cu}$ NPs were synthesized by the chemical reduction method in an aqueous medium using $\mathrm{CuSO}_{4} \cdot 5 \mathrm{H}_{2} \mathrm{O}$ as the metal precursor, hydrazine as a reduction agent, and $\mathrm{NaOH}$ as a $\mathrm{pH}$ stabilizer in the reaction medium. Several stabilizing agents were evaluated, such as polyethylenimine (PEI), a blend of polyethylenimine and allylamine (PEI/AAM), and a blend of polyethylenimine and 4-aminobutyric acid (PEI/AABT).

In addition, a study regarding antimicrobial activity toward Pseudomonas aeruginosa and Staphylococcus aureus bacteria was carried out. The current interest in exploring metal NPs for antimicrobial applications is linked to the growing microbial resistance to multiple antimicrobial agents and the development of resistant strains [33]. A common practice to analyze bacterial protection comprises an evaluation of antimicrobial activity toward Gram-positive and Gram-negative bacteria, since the resistance of both types of bacteria to traditional antibiotics is a matter of concern in the health area. Some examples of Gram-positive bacteria are Staphylococcus aureus and Enterococcus, while examples of Gramnegative include Escherichia coli, Klebsiella pneumoniae, Pseudomonas aeruginosa, and the Acinetobacter species [34].

\section{Materials and Methods}

\subsection{Materials}

The synthesis of $\mathrm{Cu}$ NPs was carried out using branched polyethylenimine (PEI), $\mathrm{Mn} \sim 1800$ by GPC, $\mathrm{Mw} \sim 2000$ by light scattering (Ls), $50 \mathrm{wt} . \%$ in $\mathrm{H}_{2} \mathrm{O}$, allylamine (AAM) ACS reagent $\geq 98 \%$, 4-aminobutyric acid (AABT) ACS reagent $\geq 99 \%$, sodium hydroxide $(\mathrm{NaOH})$ ACS reagent $\geq 97 \%$, and copper (II) sulfate pentahydrate $\left(\mathrm{CuSO}_{4} \cdot 5 \mathrm{H}_{2} \mathrm{O}\right)$ ACS reagent $\geq 98 \%$. All chemicals were supplied by Sigma Aldrich (St. Louis, MO, USA) and were used as received without further treatment.

\subsection{Synthesis of $\mathrm{Cu} N P$ s}

In a $500 \mathrm{~mL}$ ball flask partially immersed in an oil bath at $60{ }^{\circ} \mathrm{C}, 1.0 \mathrm{~g}$ of $\mathrm{CuSO}_{4} \cdot 5 \mathrm{H}_{2} \mathrm{O}$ was dissolved in $66 \mathrm{~mL}$ of deionized water with mechanical stirring. Then, the stabilizing agents (1.4 $\mathrm{g}$ of AABT or $10.3 \mathrm{~g}$ of AAM), dissolved in $20 \mathrm{~mL}$ of water, were added. The flask was kept in agitation for $10 \mathrm{~min}$. Then, $0.123 \mathrm{~g}$ of PEI dissolved in $20 \mathrm{~mL}$ of $\mathrm{H}_{2} \mathrm{O}$ was added, followed by the slow addition of $60 \mathrm{~mL}$ of $0.5 \mathrm{M} \mathrm{NaOH}$. The mixture was left to react for $30 \mathrm{~min}$, and then $4.8 \mathrm{~mL}$ of hydrazine was added to obtain a solution $\mathrm{pH}$ of 12 . The reaction was maintained for $60 \mathrm{~min}$ at $60^{\circ} \mathrm{C}$ with constant stirring. Then, the reaction mixture was allowed to reach room temperature, and the $\mathrm{Cu}$ NPs were quickly purified to avoid oxidation.

The $\mathrm{Cu}$ NPs separation from the solution was performed by centrifugation at $13,000 \times \mathrm{rpm}$ for $20 \mathrm{~min}$ at room temperature, followed by two wash steps with acetone and centrifugation under the same conditions. Finally, the $\mathrm{Cu}$ NPs were dried in a vacuum oven at $70{ }^{\circ} \mathrm{C}$ for $5 \mathrm{~h}$.

\subsection{Characterization Techniques}

X-ray diffraction (XRD): For this test, a Siemens D-5000 diffractometer (Aubrey, TX, USA) with a scanning interval in the 20 scale from $20^{\circ}$ to $80^{\circ}$ and a scan speed of $0.02 \%$ was used. Copper K $\alpha$ radiation was employed with a wavelength of $1.54 \AA$. Values of $25 \mathrm{~mA}$ and $35 \mathrm{kV}$ were used for intensity and voltage, respectively.

Thermogravimetric analysis (TGA) (TA instruments Inc., New Castle, PA, USA): A DuPont Instruments 951 analyzer was utilized. The operating conditions consisted of a heating rate of $10{ }^{\circ} \mathrm{C} / \mathrm{min}$ and an air atmosphere with a gas flow of $50 \mathrm{~mL} / \mathrm{min}$. The samples run were performed from $30^{\circ} \mathrm{C}$ to $600{ }^{\circ} \mathrm{C}$ in an $\mathrm{N}_{2}$ atmosphere. Once 
$600{ }^{\circ} \mathrm{C}$ was reached, the $\mathrm{N}_{2}$ atmosphere was switched to $\mathrm{O}_{2}$ for a better combustion of organic components.

Fourier-transform infrared spectroscopy (FTIR) (PerkinElmer Inc., Waltham, MA, USA): FTIR was used to obtain the FTIR spectra. $\mathrm{Cu}$ NPs were blended with moisture-free potassium bromide $(\mathrm{KBr})$, and a thin disk was prepared with this mixture. The disks were analyzed in the spectral range from $400 \mathrm{~cm}^{-1}$ to $4000 \mathrm{~cm}^{-1}$. This analysis was used to identify the presence of the organic coatings on the nanoparticles surface.

Zeta potential: The zeta potential analysis was carried out in a Zetasizer Nano ZS equipment from Malvern Instruments Ltd., Malvern, UK. The Cu NPs were previously dispersed for 5 min with an ultrasound, using distillated water as dispersion medium.

\subsection{Antibacterial Activity}

The antibacterial activity of Cu-PEI/AABT NPs sample was determined according to methods reported in ASTM E2149-01. Pseudomonas aeruginosa (ATCC 13388) Gram-negative and Staphylococcus aureus (ATCC 6538) Gram-Positive were used for the tests, they were purchased from American Type Culture Collection (Manassas, VA, USA). The procedure to evaluate the antibacterial activity was recently reported by our research group [35].

The antibacterial activity of the composites was calculated using Equation (1) [36], where $C_{o}$ is the number of formed CFUs (colony-forming units) in the control dish (bacterial solution without sample), and $C$ is the number of formed CFUs in the dishes where the bacterial solution was in contact with the sample.

$$
\text { Antibacterial activity }(\%)=\frac{C_{o}-C}{C_{o}} \times 100
$$

\section{Results and Discussion}

\subsection{X-ray Diffraction Analysis of $\mathrm{Cu} N \mathrm{NP}$}

Figure 1 shows the X-ray diffractograms of the $\mathrm{Cu}$ NPs synthesized with different stabilizers, identified as (a) PEI, (b) PEI/AABT, and (c) PEI/AAM. In all samples, the composition of the nanoparticles was mostly metallic $\mathrm{Cu}$. The diffraction peaks at the $2 \theta$ scale at $43^{\circ}, 50^{\circ}$, and $74^{\circ}$ correspond, respectively, to crystallographic planes (111), (200), and (220), which are the principal diffraction angles for $\mathrm{Cu}$ reported by the International Centre for Diffraction Data JCDPS [37-39]. The synthesis of Cu NPs was performed at a constant $\mathrm{pH}$ of 12.0, a condition that favors the formation of $\mathrm{CuO}$ and $\mathrm{Cu}_{2} \mathrm{O}$. However, no oxidized copper species were detected. This suggests that the nitrogen-based ligands are effective in preventing the oxidation of $\mathrm{Cu}$ NPs during synthesis.

The Debye-Scherrer equation (Equation (2)) [40] was applied to calculate the average particle diameter using the mean width of the diffraction peak located at $2 \theta$ of $43.3^{\circ}$ for $\mathrm{Cu}$ :

$$
\mathrm{D}=\mathrm{K} \lambda / \beta \cos \theta
$$

where $\mathrm{D}$ is the particle diameter, $\mathrm{K}$ is the Scherrer constant (0.89), $\lambda$ is the radiation wavelength $(\mathrm{Cu}=1.54056 \AA), \beta$ is the mean width of the most intense diffraction peak (in radians), and $\theta$ is the Bragg diffraction angle. The diameter of the PEI-, PEI/AABT-, and PEI/AAM-stabilized particles showed an average particle size of $24.3 \mathrm{~nm}, 26.6 \mathrm{~nm}$, and $19.3 \mathrm{~nm}$, respectively. These results suggest that a higher content of the stabilizer (see Section 3.2) decreases the size of the nanoparticles, as reported by other authors [11]. 


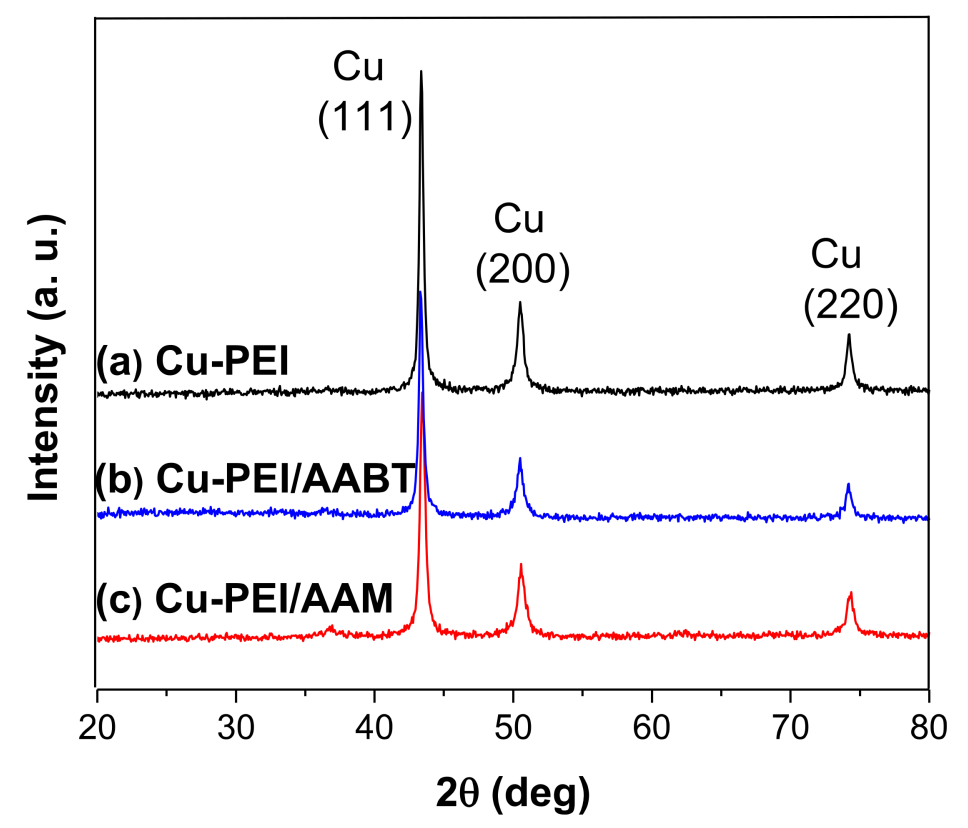

Figure 1. XRD diffractograms of $\mathrm{Cu}$ NPs synthesized with different stabilizers. (a) Cu-PEI NPs, (b) Cu-PEI/AABT NPs, and (c) Cu-PEI/AAM NPs.

\subsection{Thermogravimetric Analysis (TGA)}

Figure 2 shows the weight loss percentage (2a) and DTG (2b) curves obtained from the TGA analysis of the stabilizers. PEI showed a weight loss of $17 \%$ around $100^{\circ} \mathrm{C}$, followed by a stable weight plateau, and then a strong degradation between $300{ }^{\circ} \mathrm{C}$ and $425{ }^{\circ} \mathrm{C}$. The DTG curve of PEI (Figure 2b) shows two important degradation peaks at $312^{\circ} \mathrm{C}$ and $404^{\circ} \mathrm{C}$. With AABT, thermal degradation occurred in a single step at $211^{\circ} \mathrm{C}$, as shown in the DTG curve of AABT. AAM exhibited a weight loss from the beginning of heating, showing a degradation peak at $149^{\circ} \mathrm{C}$ in the DTG curve. The TGA analysis revealed that the low molecular weight ligands were less thermally stable than the PEI polymeric ligands.
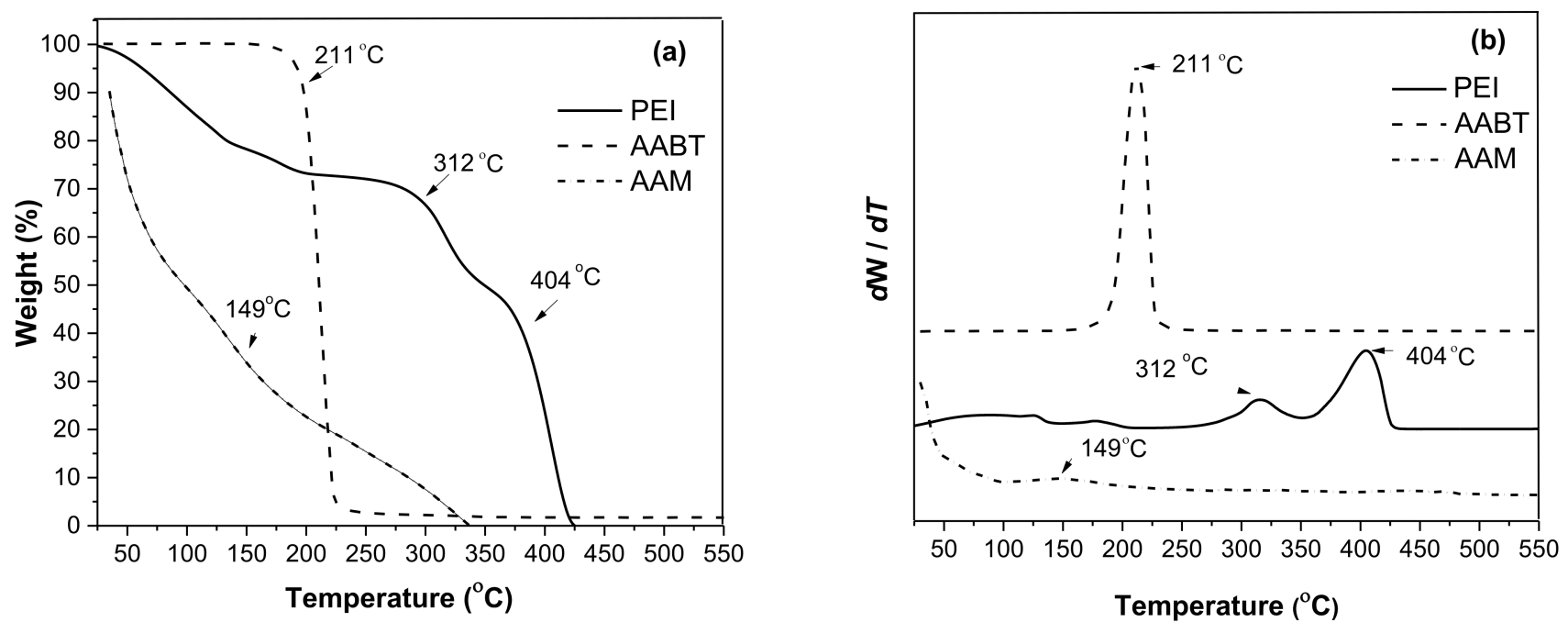

Figure 2. TGA thermograms of the stabilizers (a) and DTG curves of the stabilizers (b).

The weight loss curves corresponding to the $\mathrm{Cu}$ NPs samples synthesized with the PEI, PEI/AABT, and PEI/AAM stabilizers are shown in Figure 3a. The organic coating content was estimated from the residual weight value at $600{ }^{\circ} \mathrm{C}$, obtaining a value of $4.6 \%$ for PEI, $8.7 \%$ for PEI/AABT, and $10.7 \%$ for PEI/AAM. All samples showed an increase 
in thermal decomposition as the temperature increased, but the behavior of the weight loss curves was different than that of the stabilizers alone. Upon reaching $600{ }^{\circ} \mathrm{C}, \mathrm{O}_{2}$ was supplied for better combustion of the organic material. This caused the oxidation of the copper, which resulted in a weight gain at $600{ }^{\circ} \mathrm{C}$ in all samples.
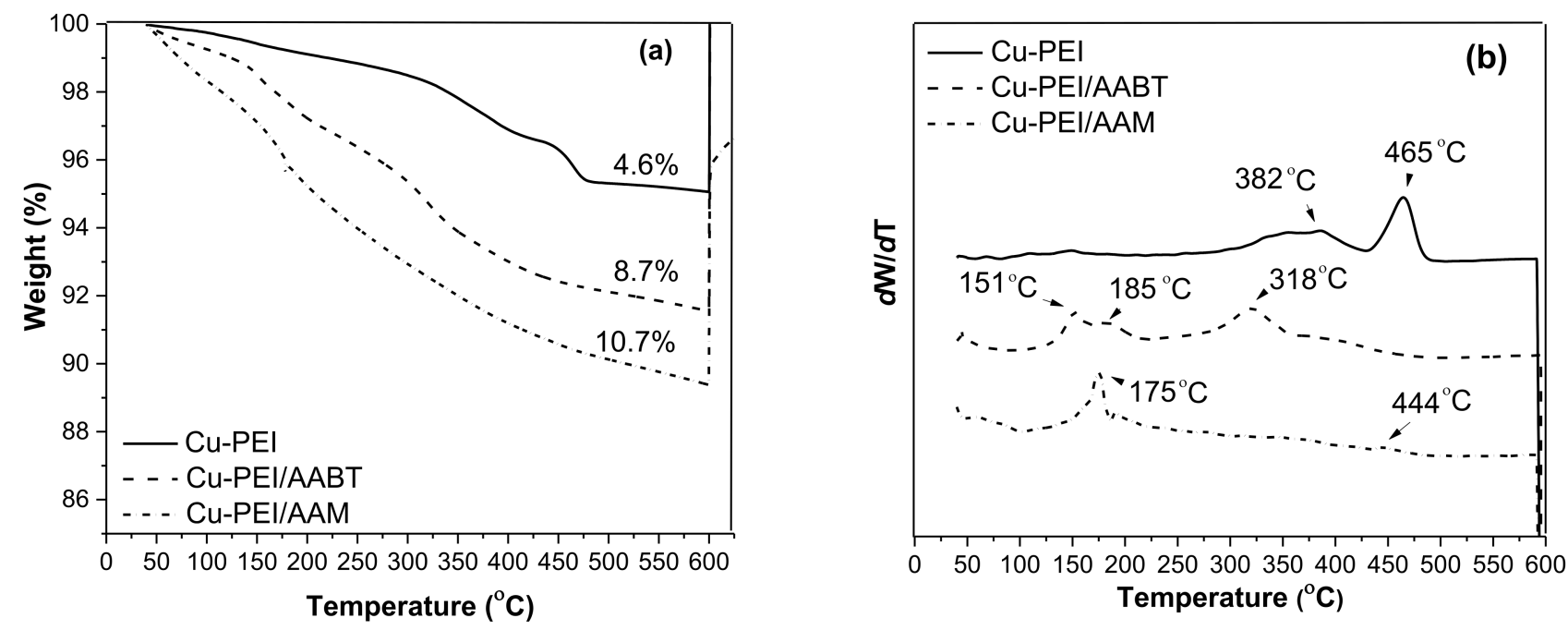

Figure 3. TGA thermograms of the Cu NPs with different ligands (a) and DTG curves of the Cu NPs with different ligands (b).

The DTG curves, presented in Figure 3b, also show different behaviors between the curves corresponding to the $\mathrm{Cu}$ NPs coated with the ligands and the curves corresponding to the organic ligands. The decomposition peak temperatures of the Cu-PEI NPs, $\mathrm{Cu}-\mathrm{PEI} / \mathrm{AABT}$ NPs, and Cu-PEI/AAM NPs samples (Figure 3b) were higher than the temperatures obtained for the stabilizers (Figure $2 \mathrm{~b}$ ). This behavior suggests a strong interaction between the copper and the polar groups of the stabilizers. Such interaction could be an advantage in producing polymeric nanocomposites [35], but could also have negative effects on other applications, such as electrically conductive materials, where it is desirable to remove the coating from $\mathrm{Cu} \mathrm{NPs}$ at low temperatures [17]. At $600^{\circ} \mathrm{C}$, complete thermal degradation of the organic material and weight gain as a result of oxidation of the metallic copper was observed.

The reaction yield calculation for the synthesis of $\mathrm{Cu}$ NPs and the particle diameter were obtained according to procedures reported previously [20], and the results are shown in Table 1. As mentioned above, there was a relationship between the ligand content and the average particle size. In all cases, the particle size was relatively small, similar to those obtained in other studies using the chemical reduction method.

Table 1. Cu NPs synthesis results.

\begin{tabular}{|c|c|c|c|c|}
\hline Ligand & $\mathrm{Cu}^{\mathrm{a}}(\%)$ & Yield (\%) & Ligand $^{a}(\%)$ & Average Particle Size ${ }^{b}(\mathrm{~nm})$ \\
\hline PEI & 95.4 & 89.6 & 4.6 & $24.3 \pm 0.4$ \\
\hline $\mathrm{PEI} / \mathrm{AABT}$ & 91.3 & 90.9 & 8.7 & $26.6 \pm 0.4$ \\
\hline PEI/AAM & 89.3 & 86.3 & 10.7 & $19.3 \pm 0.4$ \\
\hline PAAm ${ }^{\mathrm{c}}$ & 96.8 & 86.0 & 3.2 & $24.0 \pm 0.4$ \\
\hline $\mathrm{AAM}^{\mathrm{C}}$ & 94.4 & 36.0 & 5.6 & $30.0 \pm 0.4$ \\
\hline PEI ${ }^{d}$ & 87.5 & - & 12.5 & 8.5 \\
\hline
\end{tabular}

${ }^{\text {a }}$ determined by TGA, ${ }^{\text {b }}$ determined by XRD, ${ }^{\mathrm{c}}$ Ref. [20], ${ }^{\mathrm{d}}$ Ref. [17].

It is interesting to compare these results with others reported in the literature. For instance, Cadenas-Pliego and coworkers used allylamine (AAm) and polyallylamine (PAAm) for the synthesis of $\mathrm{Cu}$ NPs, reporting an average particle size and ligand wt.\% similar to the values presented in Table 1 [20]. Pulkkinen and coworkers obtained an average particle 
size of $8.5 \mathrm{~nm}$ and a higher ligand wt.\% using PEI $(\mathrm{Mw}=1200)$. The difference in the results can be attributed to the reaction conditions employed and the use of PEI with a low molecular weight [17].

\subsection{Transmission Electron Microscopy Analysis (TEM)}

The morphology of $\mathrm{Cu}$ NPs was determined by transmission electron microscopy analysis (TEM). Figure 4 a shows the micrograph of the synthesized nanoparticles in the presence of PEI, which presents a spheric morphology. The micrograph obtained at a high resolution indicates that the $\mathrm{Cu}$ NPs had a coating (PEI) on their surface with an estimated thickness of $4.2 \mathrm{~nm}$. Figure $4 \mathrm{~b}$ shows the micrograph of the nanoparticles synthesized in the presence of the PEI/AABT blend. Single spherical particles were observed, as well as some aggregates. The nanoparticles synthesized in the presence of the PEI/AAM blend also presented a spherical morphology. The micrographs obtained with a high resolution also provide evidence of the coating on the Cu NPs (Figure 4c).
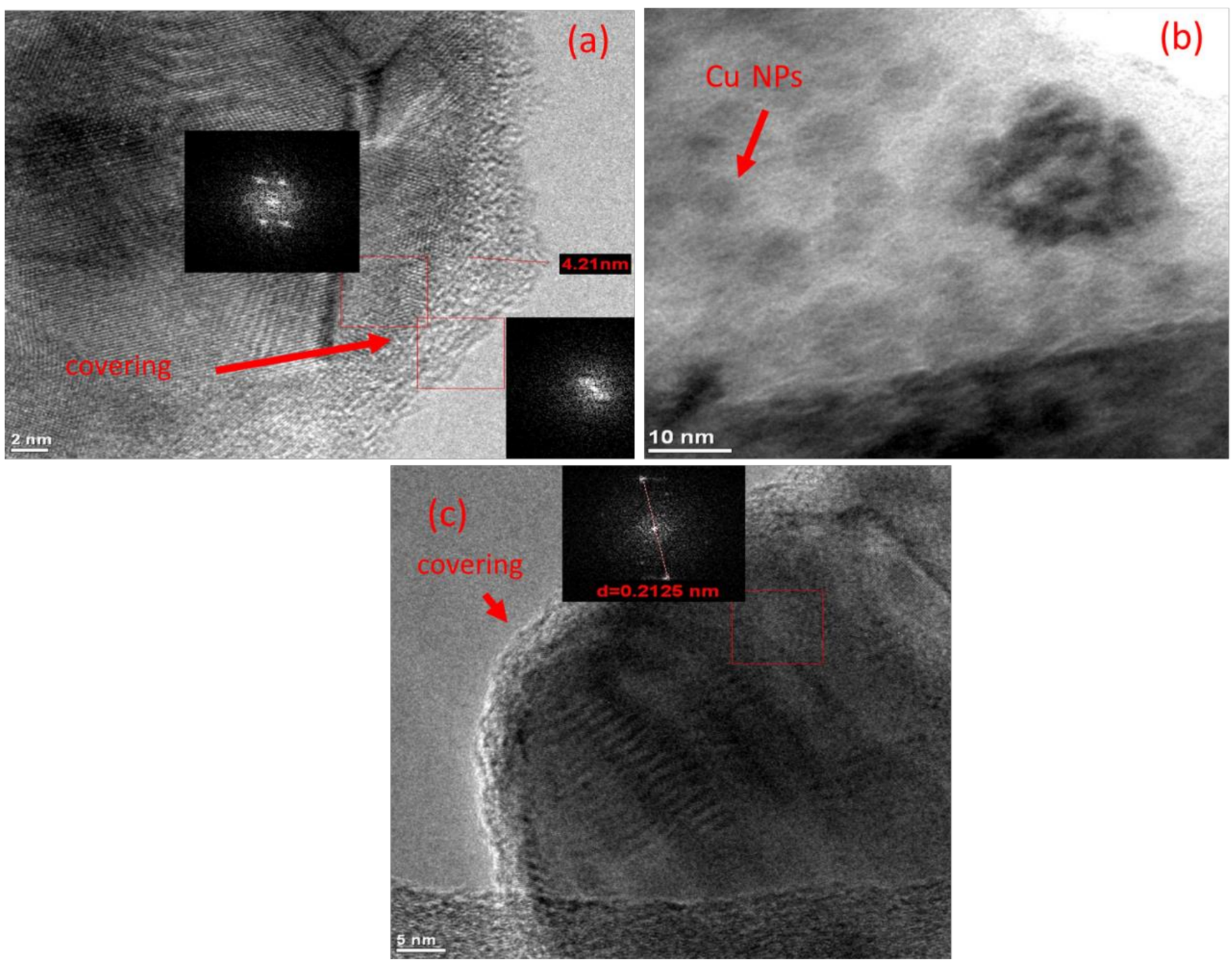

Figure 4. TEM micrographs of (a) Cu-PEI NPs, (b) Cu-PEI/AABT NPs, and (c) Cu-PEI/AAM NPs.

\subsection{Fourier Transform Infrared Spectroscopy Analysis (FTIR)}

Through FTIR analysis, it was possible to determine the presence of PEI, AAM, and AABT on the surface of the Cu NPs. To determine whether the copper was coordinated with the amino groups of the stabilizers, we analyzed whether there was a shift in the absorption bands corresponding to the $\mathrm{C}-\mathrm{N}$ or $\mathrm{N}-\mathrm{H}$ bond. A shift change suggests the 
interaction of nitrogen with the copper atom, as proposed as an explanation for similar systems [41].

The FTIR spectra of the pure PEI, AAM, and AABT stabilizers are illustrated in Figure 5, and the characteristics absorption bands are shown in Table 2.

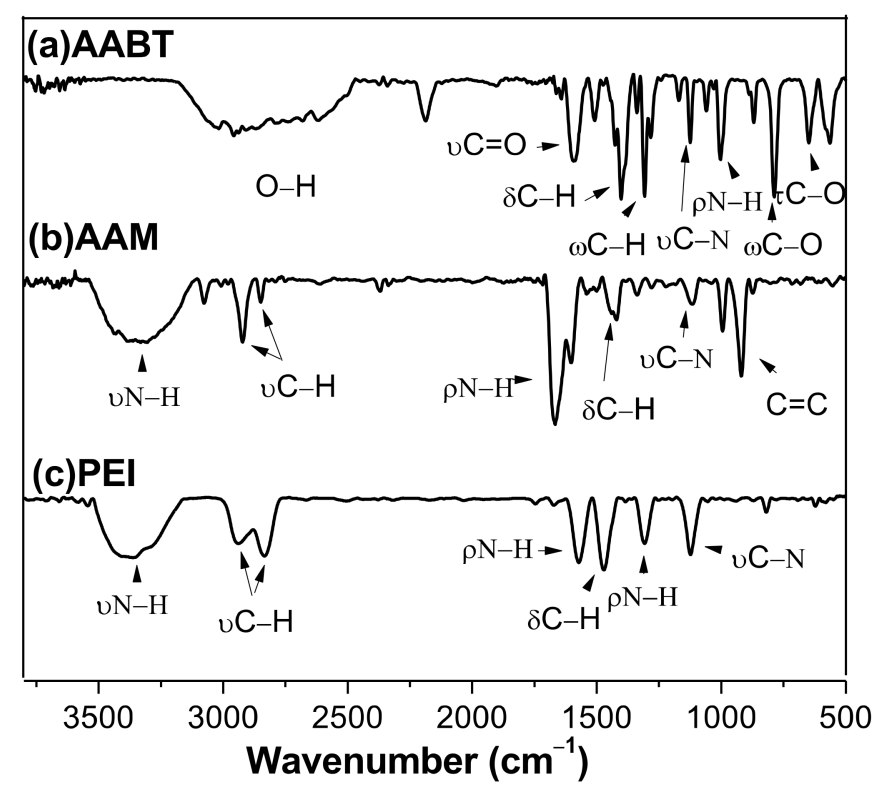

Figure 5. FTIR spectra of (a) AABT, (b) AAM, and (c) PEI.

Table 2. FTIR spectral data $\left(\mathrm{cm}^{-1}\right)$ of PEI, AAM, and AABT [42-52].

\begin{tabular}{cccc}
\hline Assignment & PEI & AAM & AABT \\
\hline Stretching N-H & 3360 & 3370 & 3380 \\
Stretching C-H & $2950^{\mathrm{a}}$ & $2920^{\mathrm{a}}$ & 2960 \\
Bending N-H & $2830^{\mathrm{s}}$ & $2840^{\mathrm{s}}$ & 2940 \\
& 1570 & 1670 & 1010 \\
Bending C-H & 1310 & 1420 & 1400 \\
Stretching C-N & 1480 & & 1310 \\
Stretching C=O & 1120 & 1120 & 1120 \\
C=C & & 920 & 1600 \\
Bending C-O & & & 789 \\
& & & 648 \\
\hline
\end{tabular}

a asymmetrical, ${ }^{\mathrm{s}}$ symetrical.

Figure 6 presents the FTIR spectra of the Cu-PEI NPs, Cu-PEI/AAM NPs, and CuPEI/AABT NPs samples. The spectra include the characteristic bands of the pure PEI with some differences in the wavelength values. The N-H bond bending signal at $1310 \mathrm{~cm}^{-1}$ and the C-N bond stretching signal at $1120 \mathrm{~cm}^{-1}$ were slightly wider and changed in their displacement compared to pure PEI signals. These changes can be explained by the coordination of copper to the free electron pair of the nitrogen atom. The presence of AAM is difficult to visualize because it has the same $-\mathrm{NH}_{2}$ functional group as PEI, and the band corresponding to the $\mathrm{C}=\mathrm{C}$ group was not observed. This can be attributed to two factors: (1) a low AAM content in the sample, and (2) a possible polymerization reaction. A similar explanation was reported for $\mathrm{Cu}$ NPs synthesized in the presence of a blend of polyallylamine/allylamine [27]. With the Cu NPs synthesized in the presence of the blend PEI/AABT, the most characteristic signal that suggests the existence of AABT is the corresponding to $\mathrm{C}=\mathrm{O}$ group at $1600 \mathrm{~cm}^{-1}$. Unfortunately, this band overlapped with the 
$\mathrm{N}-\mathrm{H}$ band of the PEI. However, the bending signals in the wagging and twisting mode of the C-O bond can be observed [42-45].

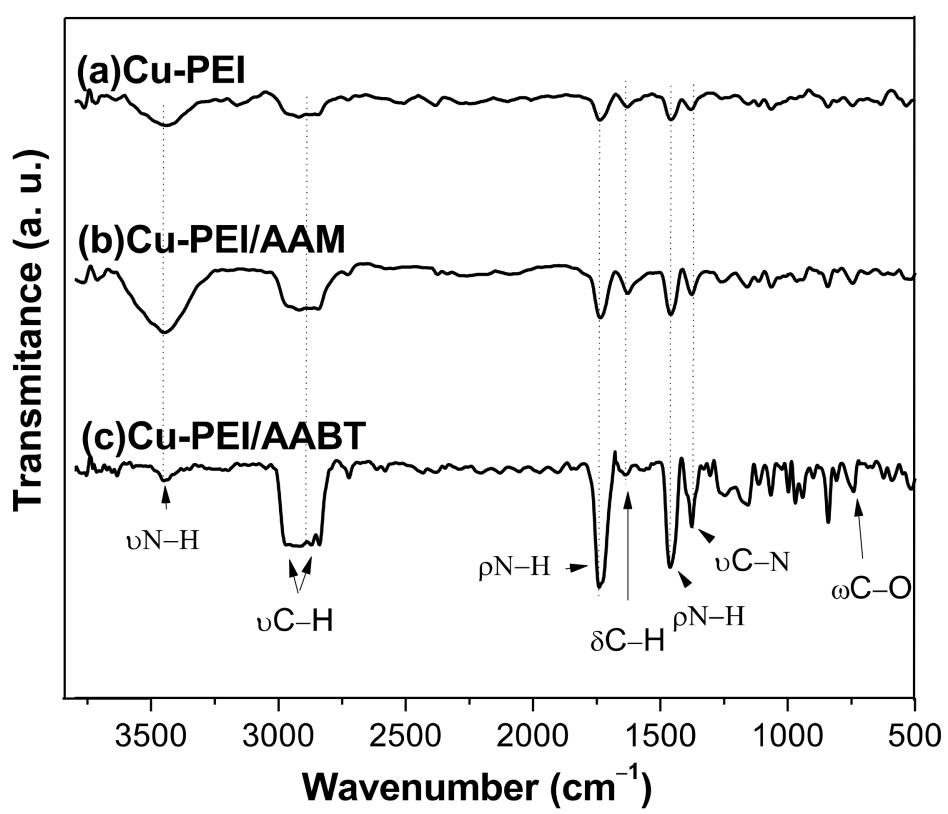

Figure 6. FTIR spectra of the Cu NPs with different stabilizers, (a) Cu-PEI; (b) Cu-PEI/AAM; (c) Cu-PEI/AABT.

\subsection{Zeta Potential Analysis of $\mathrm{Cu} N \mathrm{NPS}$}

The Cu-PEI NPs, Cu-PEI/AAM NPs, and Cu-PEI/AABT NPs samples were analyzed by zeta potential analysis. The comparison of the results provides a measure of the dispersion capability of the $\mathrm{Cu}$ NPs with different stabilizers. The samples were dispersed in distilled water by ultrasound, and the zeta potential was immediately measured. The obtained values were $-68.1 \mathrm{mV},-82.8 \mathrm{mV}$, and $-68.6 \mathrm{mV}$, respectively. All samples had negative values lower than $-30 \mathrm{mV}$. This result suggests good colloidal stability of the $\mathrm{Cu}$ NPs and can be attributed to the high coating content (see Section 3.2). The highest negative value was achieved by the $\mathrm{Cu} \mathrm{PEI} / \mathrm{AAM}$ NPs sample, which also had the highest organic coating content $(10.7 \%)$. All solutions maintained good colloidal stability, as there are no signs of precipitation after $10 \mathrm{~h}$. For all solutions, signs of precipitation were only observed after $24 \mathrm{~h}$. Figure 7 shows pictures of the solutions at 10 and $24 \mathrm{~h}$ after the dispersion of the $\mathrm{Cu}$ NPs. 


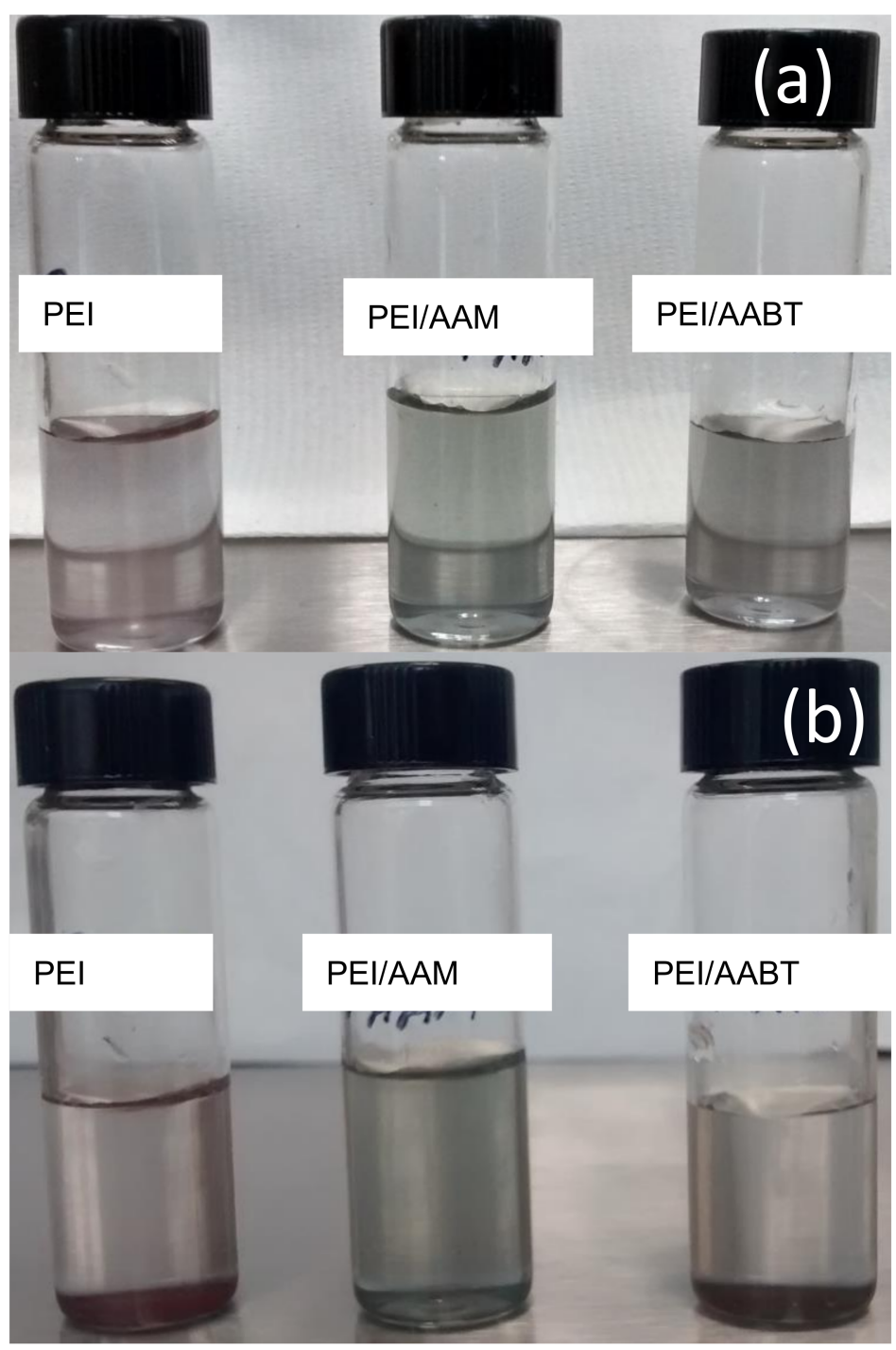

Figure 7. Colloidal stability of the Cu NPs (a) after $10 \mathrm{~h}$ of dispersion, and (b) after $24 \mathrm{~h}$ of dispersion.

\subsection{Antibacterial Activity of Cu-PEI/AABT NPS}

The Cu-PEI/AABT NPs samples were selected for evaluation in an antibacterial activity test, since these nanoparticles obtained the highest yield and showed a good dispersion in water after ultrasonication. The minimum bactericidal concentration (MBC), which was also obtained in this study, is defined as the lowest concentration of an antimicrobial agent that kills $100 \%$ of the microorganisms.

The antibacterial activity of the $\mathrm{Cu}$ NPs was determined toward P. aeruginosa and S. aureus bacteria using Cu NPs concentrations of 50 ppm, 100 ppm, 200 ppm, 400 ppm, and $800 \mathrm{ppm}$ with contact times between 0 and $6 \mathrm{~h}$. Figures 8 and 9 show the results for both bacteria. 


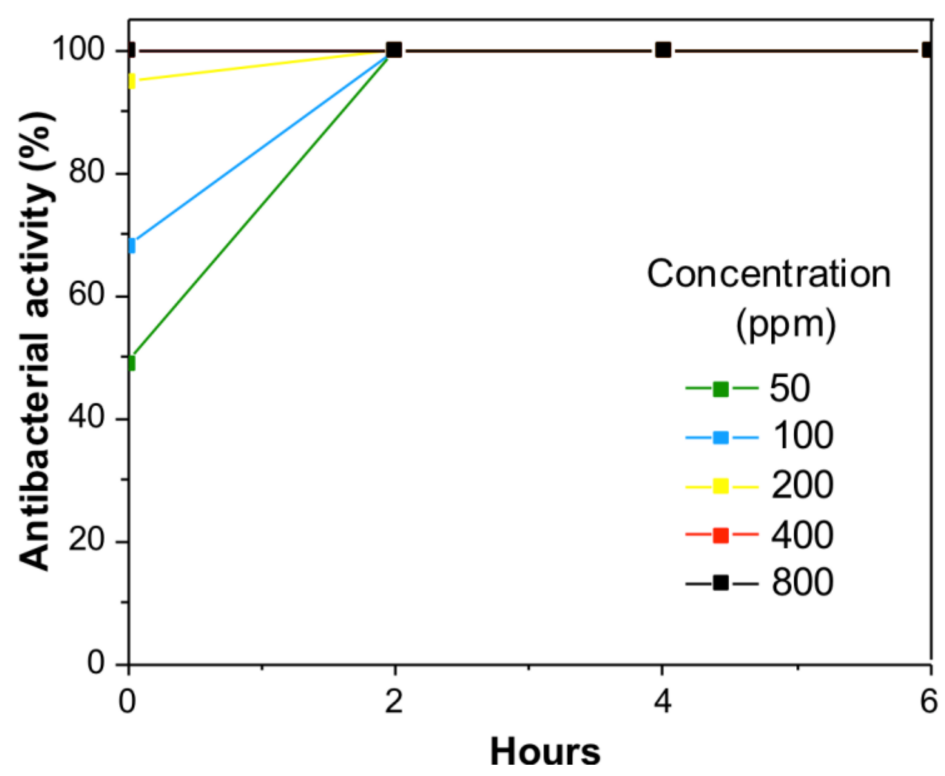

Figure 8. Percentage of the antibacterial activity of the Cu-PEI/AABT NPs against P. aeruginosa at different concentrations.

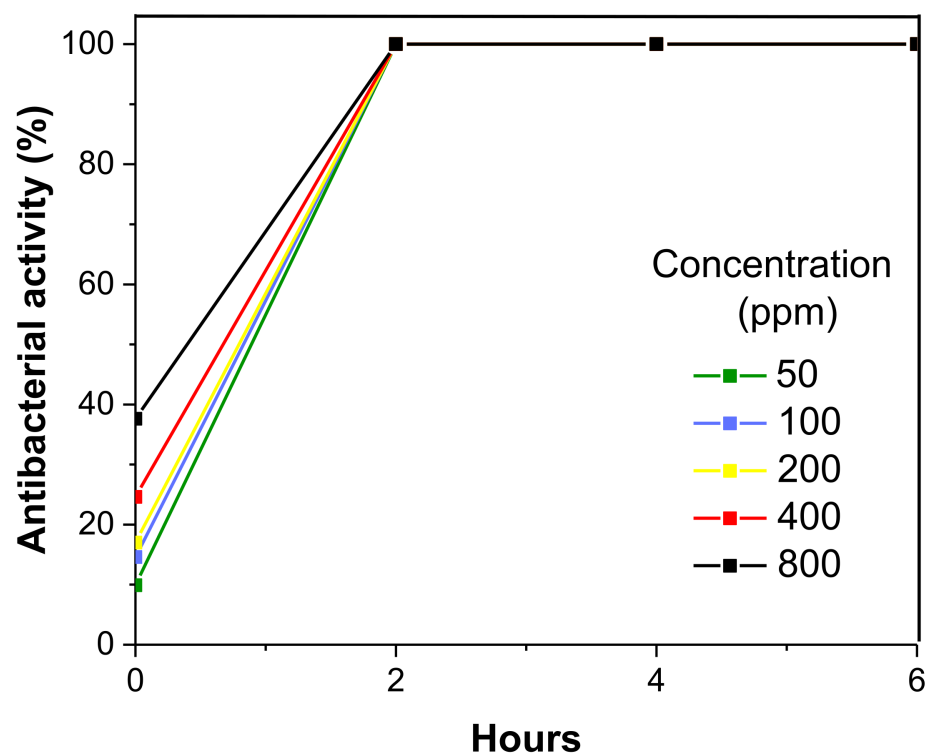

Figure 9. Percentage of the antibacterial activity of the Cu-PEI/AABT NPs against $S$. aureus at different concentrations.

The antibacterial activity plots show that the Cu NPs effectively inhibited the growth of both bacteria from the beginning of the contact time. It can be observed that the antibacterial activity increased with a higher $\mathrm{Cu}$ NPs concentration. P. aeruginosa bacteria were the most sensitive to $\mathrm{Cu}$ NPs (Figure 8). At zero contact time for the concentration of $50 \mathrm{ppm}, 100 \mathrm{ppm}, 200 \mathrm{ppm}, 400 \mathrm{ppm}$, and $800 \mathrm{ppm}$, the $\mathrm{Cu}$ NPs showed an antibacterial activity percentage of $48.9 \%, 68.2 \%, 94.9 \%$, and $100 \%$, respectively. Thus, from the first contact time, the CU NPs killed $100 \%$ of $P$. aeruginosa bacteria at a minimum bactericidal concentration (MBC) of $200 \mathrm{ppm}$. The $\mathrm{Cu}$ NPs can behave as antimicrobial agents from this concentration.

S. aureus bacteria was the most resistant to the $\mathrm{Cu}$ NPs. Even at the highest concentration of $800 \mathrm{ppm}$, only $40 \%$ inhibition was achieved at zero contact time (Figure 9). The behavior observed in Figure 9 suggests that the antibacterial activity of $99.9 \%$ was achieved 
at a contact time of $2 \mathrm{~h}$ for all the $\mathrm{Cu}$ NPs concentrations. Based on these results, we can confirm that the MBC of these $\mathrm{Cu}$ NPs was $50 \mathrm{ppm}$ at $2 \mathrm{~h}$ of contact time. These data are comparable to those reported for $\mathrm{Cu}$ NPs with high antimicrobial activity [33]. Moreover, the antimicrobial activity of the $\mathrm{Cu}$ NPs reported in this study is also comparable with commercial nanoparticles, since it has been reported that $\mathrm{Cu}$ NPs with $99.8 \%$ purity and an average particle size of $25 \mathrm{~nm}$ show an MBC toward Pseudomonas aeruginosa and Staphylococcus aureus between 800 ppm and 1600 ppm [14]. Cu NPs with high antimicrobial activity are potential candidates for applications in polymeric membranes for water purification [1].

\section{Conclusions}

The $\mathrm{Cu}$ NPs synthesis using the organic stabilizers polyethylenimine, allylamine, and 4-aminobutyric acid led to the obtention of oxide-free $\mathrm{Cu}$ NPs with high yields, small average particle size, and the ability to form stable colloidal solutions. The presence of the organic coating was confirmed by the FTIR, TEM, and TGA analyses. The colloidal stability observed in the $\mathrm{Cu}$ NPs can be attributed to the organic coating formed on their surfaces. The colloidal solution obtained with Cu-PEI/AAM NPs showed the highest stability with a zeta potential of $-82.8 \mathrm{mV}$. The antibacterial activity of Cu-PEI/AABT toward P. aeruginosa and $S$. aureus bacteria was significantly high. Cu-PEI/AABT can inhibit both bacteria with low contact times at copper concentrations between 50-200 ppm. The dispersion effortlessness of Cu NPs and their high antibacterial activity can play an important role in antimicrobial applications. Such applications may involve the direct spraying on textiles or the synthesis of polymeric nanocomposites.

Author Contributions: Conceptualization, G.C.-P., N.J.-M., M.P.-A., C.C.-A. and L.E.L.-U.; methodology, N.J.-M., M.P.-A., L.E.L.-U., E.D.B.-C., C.C.-A. and J.M.M.-P.; formal analysis, J.M.M.-P., M.P.-A., E.D.B.-C., C.C.-A. and N.J.-M.; investigation, G.C.-P., J.M.M.-P., L.E.L.-U., C.C.-A. and M.P.-A.; writing-original draft preparation, N.J.-M., G.C.-P., M.P.-A. and L.E.L.-U.; writing-review and editing, N.J.-M., M.P.-A. and G.C.-P. All authors have read and agreed to the published version of the manuscript.

Funding: This research was funded by CONACyT-SENER-Sustentabilidad Energética, Centro Mexicano de Innovación en Energía del Océano Grant No. 0249795 and FORDECYT-PRONACES/845101/2020, grant number 845101 .

Institutional Review Board Statement: Not applicable.

Informed Consent Statement: Not applicable.

Data Availability Statement: The data presented in this study are available on request from the corresponding author.

Acknowledgments: Noemi Jardón-Maximino would like to thank CONACYT for Scholarship no. 263275. The authors would also like to thank G. Mendez Padilla, A. Espinoza Muñoz, V.E. Comparán-Padilla, J.A. Mercado Silva, J. Campos Oyervides, and R. Cedillo García for their valuable technical support.

Conflicts of Interest: The authors declare no conflict of interest.

\section{References}

1. García, A.; Rodríguez, B.; Giraldo, H.; Quintero, Y.; Quezada, R.; Hassan, N.; Estay, H. Copper-Modified Polymeric Membranes for Water Treatment: A Comprehensive Review. Membranes 2021, 11, 93. [CrossRef] [PubMed]

2. Van Doremalen, N.; Bushmaker, T.; Morris, D.H.; Holbrook, M.G.; Gamble, A.; Williamson, B.N.; Tamin, A.; Harcourt, J.L.; Thournburg, N.J.; Gerber, S.I.; et al. Aerosol and surface stability of SARS-CoV-2 as compared with SARS-CoV-1. N. Engl. J. Med. 2020, 382, 1564-1567. [CrossRef] [PubMed]

3. Zuniga, J.M.; Cortes, A. The role of additive manufacturing and antimicrobial polymers in the COVID-19 pandemic. Exp. Rev. Med. Dev. 2020, 17, 477-481. [CrossRef]

4. Kumar, S.; Karmacharya, M.; Joshi, S.R.; Gulenko, O.; Park, J.; Kim, G.-H.; Cho, Y.-K. Photoactive Antiviral Face Mask with Self-Sterilization and Reusability. Nano Lett. 2021, 21, 337-343. [CrossRef] [PubMed] 
5. Quiterio-Gutiérrez, T.; Ortega-Ortiz, H.; Cadenas-Pliego, G.; Hernández-Fuentes, A.D.; Sandoval-Rangel, A.; Benavides-Mendoza, A.; Cabrera-de la Fuente, M.; Juárez-Maldonado, A. The Application of Selenium and Copper Nanoparticles Modifies the Biochemical Responses of Tomato Plants under Stress by Alternaria solani. Int. J. Mol. Sci. 2019, 20, 1950. [CrossRef]

6. Pérez-Labrada, F.; López-Vargas, E.R.; Ortega-Ortiz, H.; Cadenas-Pliego, G.; Benavides-Mendoza, A.; Juárez-Maldonado, A. Responses of Tomato Plants under Saline Stress to Foliar Application of Copper Nanoparticles. Plants 2019, 8, 151. [CrossRef] [PubMed]

7. Hernández-Hernández, H.; Quiterio-Gutiérrez, T.; Cadenas-Pliego, G.; Ortega-Ortiz, H.; Hernández-Fuentes, A.D.; Cabrera de la Fuente, M.; Valdés-Reyna, J.; Juárez-Maldonado, A. Impact of Selenium and Copper Nanoparticles on Yield, Antioxidant System, and Fruit Quality of Tomato Plants. Plants 2019, 8, 355. [CrossRef]

8. González-García, Y.; Cárdenas-Álvarez, C.; Cadenas-Pliego, G.; Benavides-Mendoza, A.; Cabrera-de-la-Fuente, M.; SandovalRangel, A.; Valdés-Reyna, J.; Juárez-Maldonado, A. Effect of Three Nanoparticles (Se, Si and Cu) on the Bioactive Compounds of Bell Pepper Fruits under Saline Stress. Plants 2021, 10, 217. [CrossRef]

9. Bashir, F.; Irfan, M.; Ahmad, T.; Iqbal, J.; Butt, M.T.; Sadef, Y.; Moniruzzaman, M. Efficient utilization of low cost agro materials for incorporation of copper nanoparticles to scrutinize their antibacterial properties in drinking water. Environ. Technol. Innov. 2020, 21, 101228. [CrossRef]

10. Garcia, K.A.; Peroja KA, G.; Tuberon NA, L.; Cambiador CJ, B.; Cid-Andres, A.P. Metal incorporated Philippine Abaca fiber (Manila hemp) as a potential novel filter for water disinfection. J. Phys. Conf. Ser. 2021, 1, 012064. [CrossRef]

11. Wang, B.; Chen, S.; Nie, J.; Zhu, X. Facile method for preparation of superfine copper nanoparticles with high concentration of copper chloride through photoreduction. R. Soc. Chem. Adv. 2014, 4, 27381-27388. [CrossRef]

12. Navarro-Rosales, M.; Ávila-Orta, C.A.; Neira-Velázquez, M.G.; Ortega-Ortiz, H.; Hernández-Hernández, E.; Solís-Rosales, S.G.; España-Sánchez, B.L.; Gónzalez-Morones, P.; Jímenez-Barrera, R.M.; Sánchez-Valdes, S.; et al. Effect of Plasma Modification of Copper Nanoparticles on their Antibacterial Properties. Plasma Process. Polym. 2014. [CrossRef]

13. Tamayo, L.; Azócar, M.; Kogan, M.; Riveros, A.; Páez, M. Copper-polymer nanocomposites: An excellent and cost-effective biocide for use on antibacterial surfaces. Mater. Sci. Eng. C 2016, 69, 1391-1409. [CrossRef]

14. España-Sánchez, B.L.; Ávila-Orta, C.A.; Neira-Velásquez, M.G.; Solís-Rosales, S.G.; González-Morones, P. Preparation of Polymer Nanocomposites with Enhanced Antimicrobial Properties. Mater. Res. Soc. 2012, 1479, 57-62. [CrossRef]

15. Milani, M.A.; Quijada, R.; Basso, N.R.S.; Graebin, A.P.; Galland, G.B. Influence of the Graphite Type on the Synthesis of Polypropylene/Graphene Nanocomposites. J. Polym. Sci. A Polym. Chem. 2012, 50, 3598-3605. [CrossRef]

16. Harishchandra, B.D.; Pappuswamy, M.; PU, A.; Shama, G.; Arumugam, V.A.; Periyaswamy, T.; Sundaram, R. Copper Nanoparticles: A Review on Synthesis, Characterization and Applications. Asian Pac. J. Cancer Biol. 2020, 5, 201-210. [CrossRef]

17. Pulkkinen, P.; Shan, J.; Leppanen, K.; Kansakoski, A.; Laiho, A.; Jarn, M.; Tenhu, H. Poly(ethylene imine) and Tetraethylenepentamine as Protecting Agents for Metallic Copper Nanoparticles. ACS Appl. Mater. Interf. 2009, 1, 519-525. [CrossRef]

18. Pérez-Alvarez, M.; Cadenas-Pliego, G.; Pérez-Camacho, O.; Comparán-Padilla, V.E.; Cabello-Alvarado, C.J.; Saucedo-Salazar, E. Green Synthesis of Copper Nanoparticles Using Cotton. Polymers 2021, 13, 1906. [CrossRef]

19. Gawande, M.B.; Goswami, A.; Felpin, F.X.; Asefa, T.; Huang, X.; Silva, R.; Zou, X.; Zboril, R.; Varma, R.S. Cu and Cu-Based Nanoparticles: Synthesis and Applications in Catalysis. Chem. Rev. 2016, 116, 3722-3811. [CrossRef]

20. Sierra-Ávila, R.; Pérez-Álvarez, M.; Cadenas-Pliego, C.; Ávila-Orta, C.A.; Betancourt-Galindo, R.; Jiménez-Regalado, E.; JiménezBarrera, R.M.; Martínez-Colunga, J.G. Synthesis of Copper Nanoparticles Coated with Nitrogen Ligands. J. Nanomater. 2014, 1-8. [CrossRef]

21. Reverberi, A.P.; Salerno, M.; Lauciello, S.; Fabiano, B. Synthesis of Copper Nanoparticles in Ethylene Glycol by Chemical Reduction with Vanadium (+2) Salts. Materials 2016, 9, 809. [CrossRef]

22. Lai, D.; Liu, T.; Jiang, G.; Chen, G. Synthesis of Highly Stable Dispersions of Copper Nanoparticles Using Sodium Hypophosphite. J. Appl. Polym. Sci. 2013, 1443-1449. [CrossRef]

23. Wang, Y.; Asefa, T. Poly(allylamine)-Stabilized Colloidal Copper Nanoparticles: Synthesis, Morphology, and Their SurfaceEnhanced Raman Scattering Properties. Langmuir 2010, 26, 7469-7474. [CrossRef] [PubMed]

24. Wang, Y.; Biradar, A.V.; Wang, G.; Sharma, K.K.; Duncan, C.T.; Rangan, S.; Asefa, T. Controlled Synthesis of Water-Dispersible Faceted Crystalline Copper Nanoparticles and Their Catalytic Properties. Chem. Eur. J. 2010, 16, 10735-10743. [CrossRef]

25. Shahmiri, M.; Ibrahim, N.A.; Zainuddin, N.; Asim, N.; Bakhtyar, B.; Zaharim, A.; Sopian, K. Effect of pH on the Synthesis of CuO Nanosheets by Quick Precipitation Method. WSEAS Trans. Environ. Dev. 2013, 2, 137-146.

26. Shu, X.; Feng, J.; Liao, J.; Zhang, D.; Peng, R.; Shi, Q.; Xie, X. Amorphous carbon-coated nano-copper particles: Novel synthesis by Sol-Gel and carbothermal reduction method and extensive characterization. J. Alloys Compd. 2020, 848, 156556. [CrossRef]

27. Sierra-Ávila, R.; Pérez-Álvarez, M.; Cadenas-Pliego, G.; Comparán-Padilla, V.E.; Ávila-Orta, C.A.; Pérez-Camacho, O.; JiménezRegalado, E.; Hernández-Hernández, E.; Jiménez-Barrera, R.M. Synthesis of Copper Nanoparticles Using Mixture of Allylamine and Polyallylamine. J. Nanomater. 2015, 16, 140. [CrossRef]

28. Jardón-Maximino, N.; Pérez-Alvarez, M.; Sierra-Ávila, R.; Ávila-Orta, C.A.; Jiménez-Regalado, E.; Bello, A.M.; González-Morones, P.; Cadenas-Pliego, P. Oxidation of Copper Nanoparticles Protected with Different Coatings and Stored under Ambient Conditions. J. Nanomater. 2018, 2018, 9512768. [CrossRef] 
29. Xia, T.; Guan, Y.; Yang, M.; Xiong, W.; Wang, N.; Zhao, S.; Guo, C. Synthesis of polyethylenimine modified Fe3O4 nanoparticles withimmobilized Cu2+ for highly efficient proteins adsorption. Colloid. Surf. A: Physicochem. Eng. Asp. 2014, 443, 552-559. [CrossRef]

30. Deze, E.G.; Papavasiliou, A.; Papageorgiou, S.K.; Katsaros, F.K.; Kouvelos, E.P.; Romanos, G.E.; Boukos, N.; Xin, Q.; Nyalosaso, J.L.; Cool, P. Metal loaded nanoporous silicas with tailor-made properties through hyperbranched polymer assisted templating approaches. Microporous Mesoporous Mater. 2016, 235, 107-119. [CrossRef]

31. Ting-Ting, X.; Chun-Zhao, L.; Jian-Hua, H.; Chen, G. Improved performance of immobilized laccase on amine-functioned magnetic Fe3O4 nanoparticles modified with polyethylenimine. Chem. Eng. J. 2016, 295, 201-206. [CrossRef]

32. Tsiourvas, D.; Papavasiliou, A.; Deze, E.G.; Papageorgiou, S.K.; Katsaros, F.K.; Romanos, G.E.; Poulakis, E.; Philippopoulos, C.J.; Xin, Q.; Cool, P. A Green Route to Copper Loaded Silica Nanoparticles Using Hyperbranched Poly(Ethylene Imine) as a Biomimetic Template: Application in Heterogeneous Catalysis. Catalysts 2017, 7, 390. [CrossRef]

33. Bogdanović, U.; Lazić, V.; Vodnik, V.; Budimir, M.; Marković, Z.; Dimitrijević, S. Copper nanoparticles with high antimicrobial activity. Mater. Lett. 2014, 128, 75-78. [CrossRef]

34. Arendsen, L.P.; Thakar, R.; Sultan, A.H. The Use of Copper as an Antimicrobial Agent in Health Care, Including Obstetrics and Gynecology. Clin. Microbiol. Rev. 2019, 32, e00125-18. [CrossRef] [PubMed]

35. Jardón-Maximino, N.; Cadenas-Pliego, G.; Ávila-Orta, C.; Comparán-Padilla, V.; Lugo-Uribe, L.; Pérez-Alvarez, M.; Tavizón, S.; Santillán, G. Antimicrobial Property of Polypropylene Composites and Functionalized Copper Nanoparticles. Polymers 2021, 13, 1694. [CrossRef] [PubMed]

36. Damm, C.; Münstedt, H.; Rösch, A. The antimicrobial efficacy of polyamide 6/silver-nano- and microcomposites. Mater. Chem. Phys. 2008, 108, 61-66. [CrossRef]

37. Mott, D.; Galkowski, J.; Wang, L.; Luo, A.J.; Zhong, C.-J. Synthesis of Size-Controlled and Shaped Copper Nanoparticles. Langmuir 2007, 23, 5740-5745. [CrossRef]

38. Wang, W.; Wang, G.; Wang, X.; Zhan, Y.; Liu, Y.; Zheng, C. Synthesis and Characterization of Cu2O Nanowires by a Novel Reduction Route. Adv. Mater. 2002, 12, 67-69. [CrossRef]

39. Langford, J.I.; Wilson, A.J.C. Scherrer after sixty years: A survey and some new results in the determination of crystallite size. J. Appl. Crystallogr. 1978, 11, 102-113. [CrossRef]

40. Monshi, A.; Foroughi, M.R.; Monshi, M.R. Modified Scherrer Equation to Estimate More Accurately Nano-Crystallite Size Using XRD. World J. Nano Sci. Eng. 2012, 2, 154-160. [CrossRef]

41. Rivas, B.L.; Seguel, G.V. Synthesis, characterization of poly(allylamine)chelates with Cu(II), Co(II) and Ni(II). Polym. Bull. 1996, 37, 463-468. [CrossRef]

42. Suresh, D.M.; Sajan, D.; Laladas, K.P.; Joe, I.H.; Jayakumar, V.S.; Vaidyan, V.K. Vibrational Spectra of $\gamma$-Aminobutyric Acid. In Proceedings of the 2nd International Conference on Perspectives in Vibrational Spectroscopy, Kerala, India, 24-28 February 2008; Volume 1075, pp. 95-97. [CrossRef]

43. Kırımlıŏlu, G.Y.; Yazan, Y.; Erol, K.; Ünel, Ç.Ç. Gamma-aminobutyric acid loaded halloysite nanotubes and in vitro-in vivo evaluation for brain delivery. Int. J. Pharm. 2015, 495, 816-826. [CrossRef] [PubMed]

44. Vamecq, J.; Feutelais, Y.; Maurois, P.; Sghaier, M.; Dichi, E.; German-Fattal, M.; Herrenknecht, C.; Gressens, P.; Cecchelli, R.; Dehouck, L.; et al. Engineering a GABA endowed with pharmacological CNS activity when given by an extracerebral route. Med. Chem. Res. 2009, 18, 255-267. [CrossRef]

45. Rosado, M.T.S.; Duarte, M.L.R.; Fausto, R. Vibrational spectra (FT-IR, Raman and MI-IR) of $\alpha$ - and $\beta$-alanine. J. Mol. Struct 1997, 410-411, 343-348. [CrossRef]

46. El Khoury, J.M.; Caruntu, D.; Connor, C.J.O.; Jeong, K.-U.; Cheng, S.Z.D.; Hu, J. Poly(allylamine) Stabilized Iron Oxide Magnetic Nanoparticles. J. Nanopart. Res. 2007, 9, 959-964. [CrossRef]

47. Sardar, R.; Park, J.-W.; Shumaker-Parry, J.S. Polymer-Induced Synthesis of Stable Gold and Silver Nanoparticles and Subsequent Ligand Exchange in Water. Langmuir 2007, 23, 11883-11889. [CrossRef]

48. Chakraborti, S.; Joshi, P.; Chakravarty, D.; Shanker, V.; Ansari, Z.A.; Singh, S.P.; Chakrabarti, P. Interaction of PolyethyleneimineFunctionalized ZnO Nanoparticles with Bovine Serum Albumin. Langmuir 2012, 28, 11142-11152. [CrossRef]

49. Morales-Lara, F.; Domingo-García, M.; López-Garzón, R.; Godino-Salido, M.L.; Peñas-Sanjuán, A.; López-Garzón, F.J.; PérezMendoza, M.; Melguizo, M. Grafting the surface of carbon nanotubes and carbon black with the chemical properties of hyperbranched polyamines. Sci. Technol. Adv. Mater. 2016, 17, 541-553. [CrossRef]

50. Lindén, J.B.; Larsson, M.; Kaur, S.; Skinner, W.M.; Miklavcic, S.J.; Nann, T.; Kempson, I.M.; Nydén, M. Polyethyleneimine for copper absorption II: Kinetics, selectivity and efficiency from seawater. RSC Adv. 2015, 5, 51883-51890. [CrossRef]

51. Zhao, F.; Zhang, B.; Wang, J.; Tu, Z. Synthesis and properties of magnetite nanoparticles coated with poly(ethylene glycol) and poly(ethylene imine). J. Nanosci. Nanotechnol. 2013, 13, 6793-6797. [CrossRef] [PubMed]

52. Rahman, L.-U.; Shah, A.; Lunsford, S.K.; Han, C.; Nadagouda, M.; Sahle-Demessie, E.; Qureshi, R.; Khan, M.S.; Kraatz, H.-B.; Dionysiou, D.D. Monitoring of 2-butanone using a Ag-Cu bimetallic alloy nanoscale electrochemical sensor. RSC Adv. 2015, 5, 44427-44434. [CrossRef] 